\title{
Influence of vitamin D on the expression of mRNA of cytokines in the mucosa of inflammatory bowel disease patients
}

\author{
Vrablicova $Z^{1}$, Soltys $K^{2}$, Krajcovicova $A^{1}$, Sturdik ${ }^{1}$, Koller $T^{1}$, Huorka $M^{1}$, Payer $\mathbf{J}^{1}$, Stuchlik $\mathrm{S}^{3}$, \\ Killinger $\mathrm{Z}^{1}$, Jackuliak $\mathrm{P}^{1}$, Stuchlikova $\mathrm{M}^{3}$, Drahovska $\mathrm{H}^{4}$, Hlavaty $\mathrm{T}^{1}$ \\ 5th Department of Internal Medicine, Sub-department of Gastroenterology and Hepatology, University Hospital Bratislava \\ and Faculty of Medicine of Comenius University in Bratislava, Slovakia. tibor.hlavaty2@gmail.com
}

\begin{abstract}
The aim of this study was to analyze the influence of 25(OH)VD serum concentration on the expression of mRNA cytokines (IL-6, IL-8, IL-12, IL-17, IL-23, TNFa, CCR1, CCR2, CCR5, CCR9, CCL5, TLR2, TLR4, TLR5, CD207, CD206, FoxP3) in mucosa of IBD patients.

The cohort consisted of 86 IBD patients (48 CD and $38 \mathrm{UC}$ ) followed at the IBD center of University Hospital Bratislava-Ruzinov. We performed colonoscopy in each patient and took biopsies from mucosa of sigma and terminal ileum. Serum concentration of $25(\mathrm{OH})$ VD was assessed at the time of colonoscopy. mRNA was extracted from mucosal biopsy samples for each cytokine. Then we analyzed the correlation between VD and the expression of mRNA of cytokines from biopsies samples.

In $C D$ we observed a significant positive correlation of serum concentration 25(OH)VD and the expression mRNA level of IL-6. There was also trend towards significant positive correlation of the expression mRNA of TNFa, IL-10, IL-23, TLR 2 in inflamed mucosa of terminal ileum as well as the expression mRNA of CCR5 and CCR1 in non-inflamed mucosa from terminal ileum. We also found a trend towards positive correlation between 25(OH)VD and the expression mRNA of IL-23, TLR4, CD 207, CCR1, CCR5 and CD 206 in non-inflamed mucosa of sigma in UC.

VD significantly correlated with the levels of expression of several inflammatory cytokines including TNFa in colonic mucosa of patients with IBD (Tab. 4, Fig. 3, Ref. 31). Text in PDF www.elis.sk.

KEY WORDS: inflammatory bowel disease, mRNA cytokines, vitamin D.
\end{abstract}

\section{Introduction}

Inflammatory bowel diseases (IBDs) are chronic inflammatory disorders of the intestines, and include Crohn's disease (CD) and ulcerative colitis (UC), the aetiology and pathogenesis of which are not completely understood (1). Studies suggest that in IBD the loss of immune tolerance toward the enteric flora is mediated by different immune cells and cytokines $(2,3)$.

$\mathrm{CD}$ is mediated by the Th1 cytokines and characterized by increased production of TNF- $\alpha$, INF- $\gamma$, IL-12, IL-15, IL-17A, IL-18, IL-21 and IL-23 $(4,5)$. On the other hand, the cytokine profiles

${ }^{1} 5$ th Department of Internal Medicine, Sub-department of Gastroenterology and Hepatology, University Hospital Bratislava and Faculty of Medicine of Comenius University in Bratislava, Slovakia, ${ }^{2}$ Department of Molecular Biology, Faculty of Natural Sciences, Comenius University, Bratislava, Comenius Science Park Bratislava, Slovakia, ${ }^{3}$ Department of Molecular Biology, Faculty of Natural Sciences, Comenius University, Bratislava, Slovakia, and ${ }^{4}$ National transplantational Organization, Bratislava, Slovakia

Address for correspondence: $\mathrm{T}$. Hlavaty, $\mathrm{MD}, \mathrm{PhD}, 5$ th Department of Internal Medicine, Sub-department of Gastroenterology and Hepatology University Hospital Bratislava and Faculty of Medicine of Comenius University in Bratislava, Ruzinovska 6, SK-826 06 Bratislava Slovakia. Phone: +421.2 .48234770$

Acknowledgement: Supported by Grant No. APVV-0672 from the Slovak APVV agency. in inflamed areas of UC seem to exhibit increased production of the Th2-associated cytokines such as IL-5, IL-13, TNFa, IL-1 and IL-6 $(6,7)$. In addition, several studies have shown the involvement of Th17 type cytokines (IL-17, IL-23, IL-22 and IL-6) in the pathogenesis of both CD and UC $(8,9)$.

VD in adaptive immunity has a suppressive effect on Thelper-1 cells (Th-1) which produce IFN- $\gamma$ and lead to activation macrophages (10). However, it favors T-helper-2 cell (Th-2) response by the up-regulation of IL-4, IL-5 and IL-10 production by human T-cells (11-14).

In tune with its immune modulating effect, VD may influence the severity of inflammation in IBD (15). According to Sadeghian's recent meta-analysis of 63 epidemiological studies, the prevalence of vitamin D deficiency is shown in $57.7 \%$ of CD patients. As we have previously well-documented, inverse association between serum vitamin $\mathrm{D}$ and disease activity in CD was also observed (16). Other clinical data suggest an association between low 25(OH)VD serum concentration and increased disease activity in UC patients. (17). In our previous study, we have shown there is a clinically important bias between different VD assays. As our results indicate there is a need towards standard assays for 25(OH)VD measurement (18).

The identification of cytokines, chemokines and their receptors could allow the determination of key pathways/targets that uniquely cause or support colitides. However, how VD influences the mRNA expression of anti and pro-inflammatory cytokines in 
mucosa remains largely unknown. There are also limited data on how vitamin D exerts its local immunomodulatory effect on the intestinal mucosa of IBD patients.

\section{Methods and materials}

\section{Aim of the study}

The aim of this study was to investigate the effect of $25(\mathrm{OH})$ VD on the level of the mRNA expression of inflammatory, anti-

Tab. 1. Clinical characteristics of the cohort according the Montreal classification.

\begin{tabular}{lll}
\hline Baseline characteristics & $\mathrm{CD}(\mathrm{n}=48)$ & $\mathrm{UC}(\mathrm{n}=38)$ \\
\hline Sex (male / female) & $34 / 14$ & $21 / 17$ \\
\hline Median age (range) yrs & $42(24-68)$ & $46(23-70)$ \\
\hline & $\mathrm{L} 1: 19(40 \%)$ & $\mathrm{E} 1: 3(8 \%)$ \\
Location (\%) & $\mathrm{L} 2: 5(10 \%)$ & $\mathrm{E} 2: 17(45 \%)$ \\
& $\mathrm{L} 3: 23(48 \%)$ & $\mathrm{E} 3: 18(47 \%)$ \\
& $\mathrm{L} 4: 1(2 \%)$ & - \\
\hline Behavior (\%) & $\mathrm{B} 1: 12(25 \%)$ & - \\
& $\mathrm{B} 2: 17(35 \%)$ & - \\
& $\mathrm{B} 3: 19(40 \%)$ & - \\
\hline Vitamin D Range (ng/ml) & $5.2-68,4$ & $6.2-60.3$ \\
$\quad$ Median & 24.75 & 30.48 \\
\hline Therapy & $2(4 \%)$ & $2(5 \%)$ \\
Corticosteroids & $20(44 \%)$ & $17(45 \%)$ \\
Azathioprine & $26(54 \%)$ & $19(50 \%)$ \\
$\quad$ Anti-TNF alfa &
\end{tabular}

inflammatory, regulatory mediators in inflamed and non-inflamed mucosa, in CD and UC patients. Additionally, we determined and compared the mRNA expression of 18 cytokines in inflamed and non-inflamed mucosa in CD and UC patients.

\section{Cohort}

The cohort consisted of 86 patients with a diagnosis of Crohn's disease or ulcerative colitis ( $48 \mathrm{CD}, 38 \mathrm{UC}$ ), each of whom underwent a colonoscopy. The study was approved by the local ethical committee. All of the eligible patients who signed the informed consent form and agreed to participate in the study were included. The demographic and clinical characteristics of each patient are provided in Table 1.

\section{Colonoscopy and biopsies}

Biopsy specimens from the terminal ileum and sigma from inflamed mucosa and if applicable also from non-inflamed mucosa were collected from the CD patients. Biopsy specimens from sigma were collected in the same manner from UC patients. Inflamed mucosa was defined as the presence of marked hyperemia, friability, erosions or ulcers. Mucosal biopsies were immediately immersed in an RNA stabilizing solution (RNA later, Qiagen) until processed and sent for mRNA cytokine analysis the same day.

Tab. 2. The difference between the expression of mRNA of cytokines in inflamed and non-inflamed mucosa in patients with ulcerative colitis, Sigma.

\begin{tabular}{|c|c|c|c|c|c|}
\hline mRNA cytokines & $\begin{array}{c}\text { Mean } \\
\text { Inflamed mucosa } \\
{ }^{1} \Delta \mathrm{C}_{1}\end{array}$ & $\begin{array}{c}\text { Mean } \\
\text { Non-inflamed mucosa } \\
{ }^{2} \Delta \mathrm{C}_{2}\end{array}$ & $\begin{array}{c}{ }^{3} \text { Difference } \\
\text { (Inflamed-Non inflamed } \\
\text { mucosa) }\end{array}$ & ${ }^{4}$ Std. deviation & ${ }^{5} \mathrm{P}$ \\
\hline $\mathrm{TNF} \alpha$ & -5.856 & -10.467 & 4.611 & 4.471 & 0.002 \\
\hline Foxp3 & $\begin{array}{l}-7.831 \\
\end{array}$ & -10.205 & 2.373 & 1.708 & 0.001 \\
\hline IL66 & -12.530 & -12.835 & 0.305 & 1.464 & 0.006 \\
\hline$\overline{\mathrm{IL} 8}$ & -5.856 & -10.467 & 4.611 & 4,471 & 0.004 \\
\hline IL10 & -10.568 & -12.433 & 1.864 & 2.017 & 0.008 \\
\hline IL12 & -12.530 & -12.835 & 0.305 & 1.464 & 0.486 \\
\hline IL17A & -13.032 & -13.343 & 0.310 & 1.831 & 0.569 \\
\hline$\overline{\mathrm{IL} 23 \mathrm{~A}}$ & -9.647 & -11.771 & 2.124 & 2.668 & 0.019 \\
\hline TLR2 & -8.451 & -11.137 & 2.687 & 2.380 & 0.002 \\
\hline TLR4 & -12.165 & -11.878 & -0.286 & 1.644 & 0.558 \\
\hline TLR5 & -10.375 & -10.606 & 0.230 & 0.691 & 0.273 \\
\hline$\overline{\mathrm{CCR} 1}$ & -7.428 & -9.552 & 2.124 & 2.198 & 0.007 \\
\hline CCR2 & -9.355 & -10.653 & 1.299 & 1.900 & 0.037 \\
\hline CCR5 & -7.722 & -9.301 & 1.579 & 1.006 & $<0.001$ \\
\hline CCR9 & -9.566 & -9.056 & -0.510 & 1.204 & 0.170 \\
\hline CCL5 & -7.818 & -7.597 & -0.221 & 0.862 & 0.393 \\
\hline CD206 & -8.723 & -9.556 & 0.833 & 0.950 & 0.011 \\
\hline CD207 & -11.343 & -10.832 & -0.511 & 1.589 & 0.289 \\
\hline
\end{tabular}

Bonferronics correction was applied; $\mathrm{p}<0.003$ was considered significant.

$\Delta \mathrm{C}$ represents the difference in the number of PCR cycles needed to express the mRNA of the house keeping gene GAPDH and the number of PCR cycles needed to express the mRNA of the target cytokine $\Delta \mathrm{C}=\left(\Delta \mathrm{C}_{\text {house-keping gene }}-\Delta \mathrm{C}_{\text {cytokines }}\right)$.

1. $\triangle \mathrm{C}$ represents the difference in the number of PCR cycles needed to express the mRNA of the house keeping gene GAPDH and the number of PCR cycles needed to express the mRNA of the target cytokine, in inflamed mucosa

2. $\Delta \mathrm{C}_{2}$ represents the difference between the mRNA expression of the cytokine and the mRNA expression of the housekeeping gene in non- inflamed mucosa

3. Difference (Inflamed-Non inflamed mucosa): results of the difference between the expression of mRNA of cytokines in inflamed and non-inflamed mucosa of sigma positive difference means an up-regulation of the mRNA expression of the cytokine in inflamed mucosa - negative difference means a down-regulation of the mRNA expression of the cytokine in inflamed mucosa

4. Std. deviation: measure used to quantify the variation or dispersion of a set data

5. P: two-tailed p-value evaluating the null hypothesis against an alternative hypothesis in which the mean is not equal to 50 
408-415

Tab. 3. The difference between the expression of mRNA of cytokines in inflamed and non-inflamed mucosa in patients with Crohn's disease, Terminal ileum.

\begin{tabular}{|c|c|c|c|c|c|}
\hline mRNA cytokines & $\begin{array}{c}\text { Mean } \\
\text { Inflamed mucosa } \\
{ }^{1 .} \Delta \mathrm{C} 1\end{array}$ & $\begin{array}{c}\text { Mean } \\
\text { Non-inflamed mucosa } \\
{ }^{2} \cdot \Delta \mathrm{C} 2\end{array}$ & $\begin{array}{c}{ }^{3} \text { Difference } \\
\text { (Inflamed-Non inflamed } \\
\text { mucosa) }\end{array}$ & $\begin{array}{l}{ }^{4} \text { Std. } \\
\text { deviation }\end{array}$ & 5. $\mathrm{P}$ \\
\hline TNFa & -7.678 & -8.107 & 0.428 & 2.258 & 0.445 \\
\hline Foxp3 & -8.303 & -8.995 & 0.692 & 1.817 & 0.136 \\
\hline IL6 & -10.241 & -11.696 & 1.427 & 4.052 & 0.166 \\
\hline IL8 & -5.834 & -9.042 & 3.207 & 2.515 & $<0.001$ \\
\hline IL10 & -11.321 & -12.008 & 0.688 & 2.421 & 0.259 \\
\hline IL12 & -12.629 & -11.583 & -1.046 & 3.208 & 0.198 \\
\hline IL17A & -13.441 & -12.643 & -0.803 & 3.658 & 0.379 \\
\hline IL23A & -10.163 & -10.959 & 0.796 & 2.937 & 0.280 \\
\hline TLR2 & -8.940 & -9.578 & 0.636 & 2.047 & 0.218 \\
\hline TLR4 & -12.531 & -12.096 & -0.435 & 2.373 & 0.461 \\
\hline TLR5 & -11.057 & -10.575 & -0.481 & 2.089 & 0.356 \\
\hline$\overline{\mathrm{CCR} 1}$ & -7.290 & -8.767 & 1.478 & 1.862 & 0.005 \\
\hline CCR5 & -7.765 & -7.758 & -0.021 & 1.691 & 0.960 \\
\hline CCR9 & -10.752 & -10.817 & 0.064 & 2.674 & 0.922 \\
\hline CCL5 & -7.264 & -5.948 & -1.32 & 2.095 & 0.020 \\
\hline CD206 & -8.067 & -8.370 & 0.303 & 1.649 & 0.459 \\
\hline$\overline{\mathrm{CD} 207}$ & -10.491 & -9.423 & -1.068 & 2.236 & 0.066 \\
\hline
\end{tabular}

Bonferroni's correction was applied; $\mathrm{p}<0.003$ was considered significant.

$\triangle \mathrm{C}$ represents the difference in the number of PCR cycles needed to express the mRNA of the house keeping gene GAPDH and the number of PCR cycles needed to express the mRNA of the target cytokine $\Delta \mathrm{C}=\left(\Delta \mathrm{C}_{\text {house-keeping gene }}-\Delta \mathrm{C}\right.$ cytokines $)$.

1. $\triangle \mathrm{C}$ represents the difference in the number of PCR cycles needed to express the mRNA of the house keeping gene GAPDH and the number of PCR cycles needed to express the mRNA of the target cytokine ${ }_{1}$ in inflamed mucosa

2. $\Delta \mathrm{C}_{2}$ represents the difference between the mRNA expression of the cytokine and the mRNA expression of the housekeeping gene in non- inflamed mucosa

3. Difference (Inflamed-Non inflamed mucosa): results of the difference between the expression of mRNA of cytokines in inflamed and non-inflamed mucosa of sigma

- positive difference means an up-regulation of the mRNA expression of the cytokine in inflamed mucosa

- negative difference means a down-regulation of the mRNA expression of the cytokine in inflamed mucosa

4. Std. deviation: measure used to quantify the variation or dispersion of a set data

5. P: two-tailed p-value evaluating the null hypothesis against an alternative hypothesis in which the mean is not equal to 50

\section{Real time PCR (RT-qPCR)}

Tissue RNA was isolated by RNeasy Mini Kit (QIAGEN) for each cytokine (TNF $\alpha$, FOXP3, IL-6, IL8, IL-10, IL-12, IL-17, IL-23, TLR2, TLR4, TLR5 CCR1, CCR2, CCR5, CCR9, CCL5, CD207, CD 206) according to the manufacturer's instructions. RNA samples of the cytokines were converted to cDNA using Thermo Scientific Maxima H Minus First Strand cDNA Synthesis K. DNA was isolated with a DN-easy Blood \& Tissue Kit (QIAGEN). The quality and quantity of RNA was screened by an Agilent RNA 6000 Nano Kit. The gene expression of cytokines was analyzed by a custom array gene expression kit (QIAGEN) including house-keeping gene (Glyceraldehyde 3-phosphate dehydrogenase, GAPDH). Data were analyzed by RT2 Profiler PCR Array Data Analysis v3.5 software (QIAGEN). Next, we analyzed the difference between the expression of mRNA of the target cytokine and the expression of mRNA of the housekeeping gene, GAPDH. The difference was expressed as DC, which represents the difference in the number of PCR cycles needed to express the mRNA of the house keeping gene GAPDH (DC $\left.{ }_{\text {house-keeping gene }}\right)$ and the number of PCR cycles needed to express the mRNA of the target cytokine $\left(\mathrm{DC}_{\text {cytokine }}\right)$. $\mathrm{DC}=\left(\mathrm{DC}_{\text {house-keeping gene }}-\mathrm{DC}_{\text {cytokine }}\right)$.

\section{Assessment of VD serum concentration}

The serum concentration of $25(\mathrm{OH}) \mathrm{D} 3$ was measured using high-performance liquid chromatography (HPLC, Agilent 1200) at the hospital's clinical biochemistry laboratory. The parameters of the HPLC method were ultraviolet detection at $264 \mathrm{~nm}$, flow rate of $1 \mathrm{~mL} / \mathrm{min}$, temperature of $40{ }^{\circ} \mathrm{C}$, and analysis time of 10 minutes. This method measured 25(OH)D3 and 25(OH)D2.

\section{Statistical analysis}

Statistical analyses were performed using SPSS 19.0 (IBM SPSS Inc., Chicago, Illinois, United States). Nominal and ordinal variables such as clinical characteristics and VD status were analyzed using the Chi square test with Yate's correction. If any cell of the contingency table contained a value of less than 5, Fisher's exact test was used instead. The Kolmogorov-Smirnov test was used to analyze the normality of the distribution of measured parameters (age, duration of disease, VD serum concentration). We compared the expression of mRNA of cytokines ( $\Delta \mathrm{C}$, see above) in inflamed and non-inflamed mucosa using a paired sample $-\mathrm{T}$ test. The Spearman correlation coefficient was used for analyzing correlations between the serum concentration of 25-OH VD and the expression of all mRNA of cytokines in mucosal biopsies. We applied Bonferroni's correction $(n=18)$ to the baseline statistical significance level of 0.05 . The statistical significance for multiple comparisons in the study was corrected to $\mathrm{p}<0.003$. 
Tab. 4. The difference between the expression mRNA cytokines in inflamed and non-inflamed mucosa in patients with Crohn's disease, Sigma

\begin{tabular}{|c|c|c|c|c|c|}
\hline mRNA cytokines & $\begin{array}{c}\text { Mean } \\
\text { Inflamed mucosa } \\
{ }^{1} \Delta \mathrm{C}_{1} \\
\end{array}$ & $\begin{array}{c}\text { Mean } \\
\text { Non-inflamed mucosa } \\
{ }^{2} \cdot \Delta \mathrm{C}_{2} \\
\end{array}$ & $\begin{array}{c}{ }^{3} \text { Difference } \\
\text { (Inflamed-Non inflamed } \\
\text { mucosa) }\end{array}$ & ${ }^{4}$ Std. deviation & $\begin{array}{l}\text { 5. Sig. } \\
\text { (2-tailed) }\end{array}$ \\
\hline TNF & -8.204 & -8.544 & 0.341 & 1.710 & 0.504 \\
\hline Foxp3 & $\begin{array}{l}-8.558 \\
\end{array}$ & -8.558 & 0.300 & 1.837 & 0.583 \\
\hline IL6 & -11.403 & 11.783 & 0.335 & 2.723 & 0.678 \\
\hline IL8 & -7.367 & -8.424 & 1.049 & 2.363 & 0.152 \\
\hline IL10 & -11.897 & -11.969 & 0.072 & 2.078 & 0.906 \\
\hline$\overline{\mathrm{IL} 12}$ & -12.463 & $-12,357$ & -1.053 & 1.417 & 0.802 \\
\hline IL17 & -13.310 & -12.834 & -0.476 & 1.352 & 0.248 \\
\hline IL23 & -10.625 & -10.984 & 0.359 & 1.962 & 0.539 \\
\hline TLR2 & -9.832 & 10.873 & 1.039 & 2.405 & 0.162 \\
\hline TLR4 & -12.748 & -12.610 & -0.138 & 1.453 & 0.747 \\
\hline TLR5 & -10.642 & -10.660 & 0.018 & 1.227 & 0.960 \\
\hline$\overline{\mathrm{CCR} 1}$ & -8.177 & -8.856 & 0.679 & 2.546 & 0.375 \\
\hline CCR2 & -10.542 & -11.018 & 0.476 & 2.521 & 0.527 \\
\hline$\overline{\mathrm{CCR} 5}$ & -8.134 & -8.355 & 0.221 & 1.596 & 0.640 \\
\hline CCR9 & -9.514 & -9.374 & -1.395 & 1.701 & 0.782 \\
\hline CCL5 & -7.136 & -7.032 & -0.104 & 1.011 & 0.727 \\
\hline CD206 & -8.639 & -8.644 & 0.005 & 1.269 & 0.990 \\
\hline $\begin{array}{l}\text { CD207 } \\
\end{array}$ & -10.733 & -10.110 & -0.623 & 1.477 & 0.172 \\
\hline
\end{tabular}

Bonferroniфs correction was applied; $\mathrm{p}<0.003$ was considered significant.

$\Delta \mathrm{C}$ represents the difference in the number of PCR cycles needed to express the mRNA of the house keeping gene GAPDH and the number of PCR cycles needed to express the mRNA of the target cytokine $\Delta \mathrm{C}=\left(\Delta \mathrm{C}_{\text {house-keeping gene }}-\Delta \mathrm{C}\right.$ cytokines $)$

1. $\triangle \mathrm{C}$ represents the difference in the number of PCR cycles needed to express the mRNA of the house keeping gene GAPDH and the number of PCR cycles needed to express the mRNA of the target cytokine, in inflamed mucosa

2. $\Delta \mathrm{C}_{2}$ represents the difference between the mRNA expression of the cytokine and the mRNA expression of the housekeeping gene in non- inflamed mucosa

3. Difference (Inflamed-Non inflamed mucosa): results of the difference between the expression of mRNA of cytokines in inflamed and non-inflamed mucosa of sigmapositive difference means an up-regulation of the mRNA expression of the cytokine in inflamed mucosa - negative difference means a down-regulation of the mRNA expression of the cytokine in inflamed mucosa

4. Std. deviation: measure used to quantify the variation or dispersion of a set data

5. P: two-tailed p-value evaluating the null hypothesis against an alternative hypothesis in which the mean is not equal to 50

\section{Results}

\section{Study population}

The demographic and clinical characteristics are presented in in Table 1.

Analyses of the expression of mRNA of cytokines from sigma in UC patients

First, we compared the expression of mRNA of cytokines in inflamed and non-inflamed mucosa of sigma in UC patients (Tab. $2)$. We found a significantly higher expression of mRNA of cytokines TNF $\alpha(p=0.002)$, transcription factor FOXP3 $(p=0.001)$, TLR2 ( $p=0.002)$, CCR5 $(p<0.001)$ in the inflamed mucosa of sigma. There was also a trend toward a significantly higher expression of mRNA in the inflamed mucosa of sigma of IL6, IL 8, IL10, IL 23A, CCR1, CCR2, CD206.

Analyses of the expression of mRNA of cytokines from the terminal ileum in CD patients

Next, we analyzed the expression of mRNA of cytokines in inflamed and non-inflamed mucosa in the terminal ileum of CD patients. We observed a significantly higher expression of mRNA of IL- 8 in inflamed mucosa $(p \leq 0.001)$ in the terminal ileum of CD patients.
We observed a trend toward the significance of the expression of mRNA of CCL5 in non-inflamed mucosa of the terminal ileum of CD patients, also CCR1 in inflamed mucosa of the terminal ileum (Tab. 3).

Analyses of the expression of mRNA of cytokines from sigma in $C D$

We also analyzed the difference in the expression of mRNA of cytokines between inflamed and non-inflamed mucosa of sigma in CD patients (Tab. 4). We observed no significant difference between the expression of mRNA of cytokines in inflamed and non-inflamed mucosa in sigma of CD patients. The expression of mRNA of cytokines in endoscopically normal mucosa (noninflamed) was similar to the expression of mRNA of cytokines in inflamed mucosa of sigma.

Analyses of the expression of mRNA of cytokines in sigma between CD and UC patients

Finally, we compared the expression of mRNA of cytokines in sigma in inflamed as well as in non-inflamed mucosa between $\mathrm{CD}$ patients and UC patients. We found a significantly higher expression of mRNA of FOXP3 $\left(\Delta \mathrm{C}_{\mathrm{CD}}=-8.611 \mathrm{vs} \Delta \mathrm{C}_{\mathrm{UC}}=-11.342\right.$, $\mathrm{p}=0.001) \operatorname{CCL} 5\left(\Delta \mathrm{C}_{\mathrm{CD}}=-6.453, \Delta \mathrm{C}_{\mathrm{UC}}=-8.222, \mathrm{p}=0.001\right) \mathrm{CD}$ $206\left(\Delta \mathrm{C}_{\mathrm{CD}}-7.98\right.$ vs $\left.\Delta \mathrm{C}_{\mathrm{UC}}-10.758, \mathrm{p}<0.001\right)$ in non-inflamed 
mucosa in $\mathrm{CD}$ patients compared to the expression of mRNA in UC patients. Also, we observed a significantly higher expression of mRNA of IL6 $\left(\Delta \mathrm{C}_{\mathrm{CD}}=-11.110 \mathrm{vs} \Delta \mathrm{C}_{\mathrm{UC}}=-7.685, \mathrm{p}<0.002\right)$, IL12 $\left(\Delta \mathrm{C}_{\mathrm{CD}}=-11.476 \mathrm{vs} \Delta \mathrm{C}_{\mathrm{UC}}=-5.362, \mathrm{p}<0.001\right) \mathrm{TLR} 4\left(\Delta \mathrm{C}_{\mathrm{CD}}\right.$ $=-11.615$ vs $\left.\Delta \mathrm{C}_{\mathrm{UC}}-8.640, \mathrm{p}<0.001\right)$ in non-inflamed mucosa of UC patients.

The influence of the 25(OH)VD on the expression of mRNA of cytokines in patients with IBD

We analyzed the correlation between the serum concentration of $25(\mathrm{OH}) \mathrm{VD}$ and the expression of mRNA of cytokines in inflamed and non-inflamed mucosa in patients with $\mathrm{CD}$ as well as in patients with UC.

Influence of the 25(OH)VD on the expression of mRNA of cytokines in patients with $C D$

In a next group of analyses, we analyzed the correlation between the serum concentration of $25(\mathrm{OH}) \mathrm{VD}$ and the expression of mRNA of cytokines in CD patients. We found a significant positive correlation of the expression of mRNA of cytokine IL 6 $\left(r^{2}=0.2, p=0.002\right)$ in colonic samples of the inflamed terminal ileum of CD patients (Fig. 2).

In the same group, we found a trend toward a significant positive correlation between $25(\mathrm{OH}) \mathrm{VD}$ and the expression of mRNA of CCR1 in non-inflamed mucosa of sigma (Fig. 1) and CCR5 in non-inflamed mucosa of the terminal ileum (Fig. 1.)

Also, we found a trend toward a significant positive correlation of the expression of mRNA of cytokines such as TNF $\alpha$, IL10, IL 23, TLR 2 in inflamed mucosa of the terminal ileum (Fig. 2)

Influence of the 25(OH)VD on the expression of mRNA of cytokines in patients with UC

Finally, we analyzed the correlation between the serum concentration (25) OHVD and the expression of mRNA of cytokines in UC patients. We observed a trend toward a significant correlation between the serum concentration of $25(\mathrm{OH}) \mathrm{VD}$ and the mRNA expression of cytokines such as IL-23, TLR4, CCR1, CCR5,CD 206 CD207 in non-inflamed mucosa of sigma (Fig. 3).

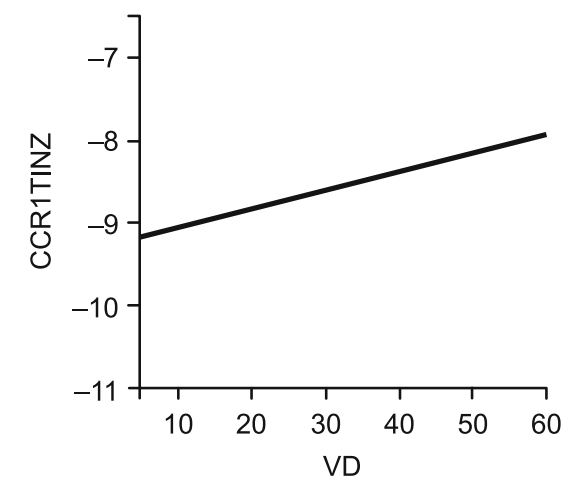

Influence of VD on the expression of mRNACCR1 in noninflamed mucosa of terminal ileum, $r^{2}=0.11, p=0.03$.

\section{Discussion}

Recent meta-analysis has shown that vitamin D influences the incidence and natural course of IBD (17). There remain questions as to whether vitamin D modifies the expression of mRNA of cytokines in the mucosa of IBD patients.

First, we analyzed the expression of mRNA in inflamed mucosa of sigma in UC patients and we found the highest up-regulation of the expression of mRNA of TNF $\alpha(p=0.002)$. Matsuda et al observed a significantly higher expression of mRNA of TNF $\alpha$ (p $=0.04$ ) in inflamed mucosa of UC patients compared to healthy controls (19).

In $C D$ patients, we demonstrated a significant up-regulation of the expression of mRNA of IL $8(\mathrm{p} \leq 0.001)$ in colonic samples of inflamed mucosa of the terminal ileum. Consistent with our results, the study by Stallmach et al found a significantly higher mRNA expression of IL 8 in biopsy specimens in active CD patients. Moreover, the mRNA transcript of IL 8 correlated with clinical disease activity (CDAI) and endoscopic scores indices (20).

Interestingly, in CD patients we observed an up-regulation of the expression of mRNA of pro-inflammatory milieu in endoscopically normally appearing mucosa. In the abovementioned study by Stallmach et al, they found a significantly higher expression of mRNA transcript of IL 1 $\beta$, IL 8, IL 23, MRP 14 in the non-inflamed area of CD patients. They showed that elevated pro-inflammatory cytokines in patients with active CD may underline disease chronicity and reactivation (20).

We also compared the level of expression of mRNA of cytokines of sigma in inflamed as well as non-inflamed mucosa between CD and UC patients. We found an up-regulation of FOXP3 $(\mathrm{p}=0.001)$, CCL5 ( $p=0.001), \operatorname{CD} 206(p<0.001)$ in non-inflamed mucosa in $\mathrm{CD}$ patients compared to the expression of mRNA in UC patients.

We observed a significantly higher level of expression of mRNA of IL6 ( $p=0.002)$, IL12 (p<0.001) TLR4 $(p<0.001)$ in the non-inflamed mucosa of UC patients.

To the best of our knowledge, there are no previously published studies that comprehensively assess the effect of VD on the expression of mRNA of cytokines in the mucosa of IBD patients.

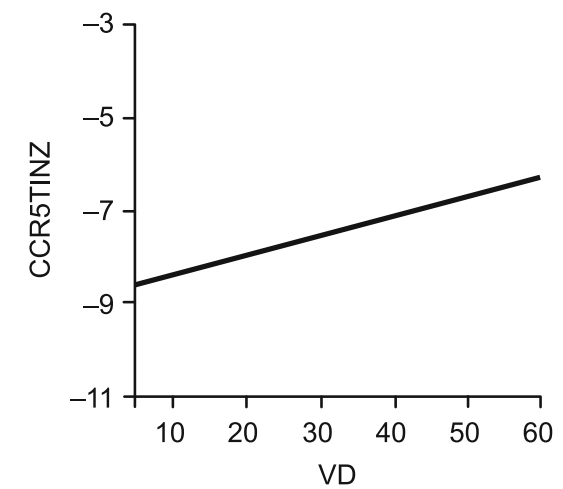

Influence of VD on the expression of mRNA CCR5 in noninflamed mucosa of terminal ileum, $r^{2}=0.17, p=0.01$.

Fig. 1. The correlation of vitamin D on mRNA expression in non-inflamed mucosa of the terminal ileum and sigma in patients with CD. 


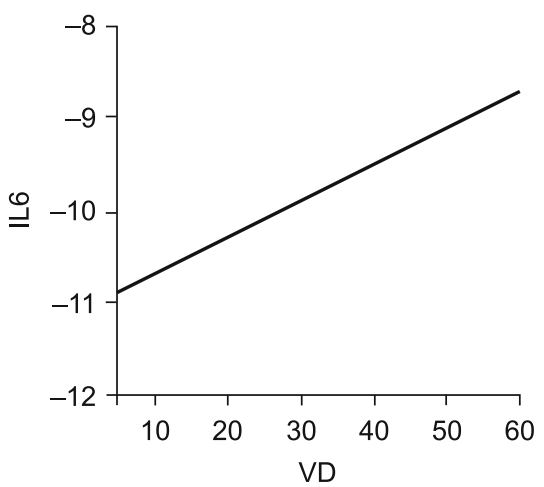

Influence of VD on the expression of mRNA IL6 in inflamed mucosa of terminal ileum, $r^{2}$ $=0.2, p=0.002$

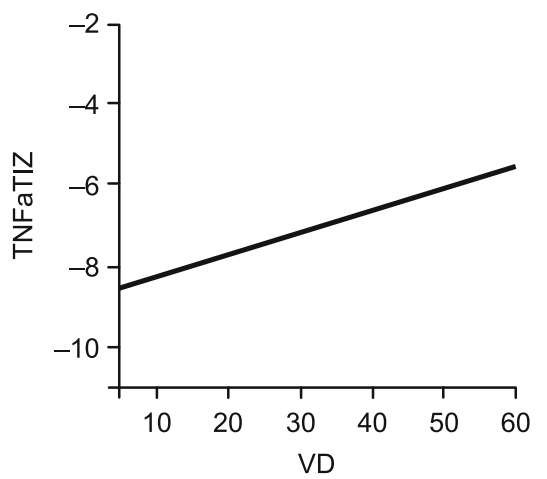

Influence of VD on the expression of mRNA TNF $\alpha$ in inflamed mucosa of terminal ileum, $r^{2}=0.17, p=0.04$

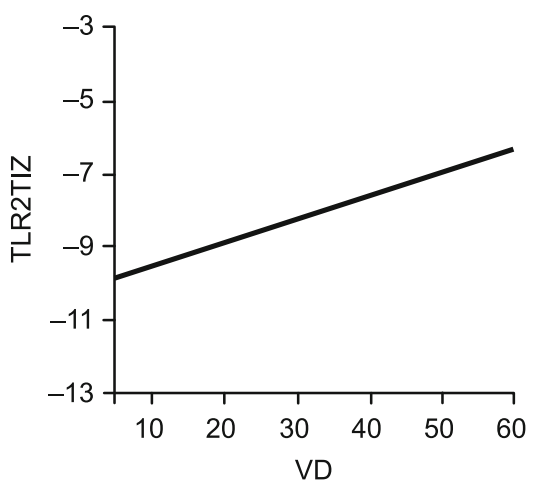

Influence of VD on the expression of mRNA TLR2 in inflamed mucosa of terminal ileum, $r 2=0.17, p=0.04$

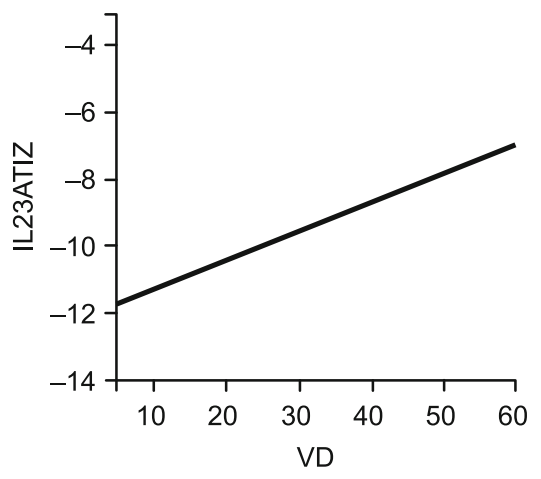

Influence of VD on the expression of mRNA IL 23 in inflamed mucosa of terminal ileum, $r^{2}$ $=0.19, p=0.03$

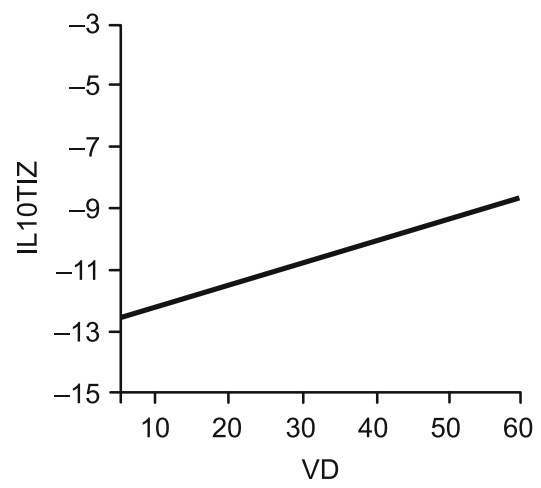

Influence of VD on the expression of mRNA IL 10 in inflamed mucosa of terminal ileum, $\mathrm{r}^{2}$ $=0.19, p=0.03$

Fig. 2. The effect of vitamin D on the mRNA expression in inflamed mucosa of the terminal ileum in patients with Crohn's disease.
In our study, we found a significant positive correlation between the serum concentration of $25(\mathrm{OH}) \mathrm{VD}$ and the expression of mRNA of IL- 6 in the inflamed mucosa in the terminal ileum of CD patients.

In the placebo-controlled study (108 CD patients) by BendixStruve et al, they showed that VD3 upregulates the expression of mRNA of IL 6 in PBMC in CD patients (21). However, it also inhibits Th-1 polarization through two independent molecular mechanisms $(22,23)$.

In a more recent study by Di Rosa, they obtained controversial results of the effect of VD on the mRNA expression of IL-1 and IL-6 in monocytes and macrophages. In monocytes, the expression of mRNA of IL1 and IL6 was upregulated by $1 \alpha, 25(\mathrm{OH})_{2} \mathrm{D}_{3}$, in contrast, $1 \alpha, 25(\mathrm{OH})_{2} \mathrm{D}_{3}$ treatment reduced basal IL-1, IL6 levels in macrophages. The expression of mRNA depends on the stage of maturation of the immune cells (monocytes/ macrophages) (24).

Kimura et al described the pleiotropic role of IL 6 that can induce Th-17 cells. They are considered to be the cause of the pathology IBD (25).

However, although $1 \alpha, 25(\mathrm{OH})_{2} \mathrm{D}_{3}$ affects the expression of mRNA of IL6 in PBMC, there is a lack of data of the influence $25(\mathrm{OH}) \mathrm{VD}$ on the expression of mRNA of IL6 in patients with inflammatory bowel disease. Our results showed that VD upregu- lates the mRNA expression of IL 6 in the inflamed mucosa of the terminal ileum in $\mathrm{CD}$ patients.

We also found a trend toward a significant correlation between the serum concentration of $25(\mathrm{OH}) \mathrm{VD}$ and the mRNA expression of TNF $\alpha$, IL 10, IL 23, TLR2 in the inflamed mucosa of the terminal ileum in $\mathrm{CD}$ patients.

There is evidence of the anti-inflammatory effect of VD on the expression of mRNA of TNF $\alpha$ in human cell lines in IBD patients (26-28). Our findings showed a trend toward a significant positive correlation (up-regulation) between vitamin $\mathrm{D}$ and the expression of mRNA of TNF $\alpha\left(r^{2}=0.17, p=0.04\right)$ in the inflamed mucosa of the terminal ileum. We concluded that vitamin $\mathrm{D}$ activates the expression of mRNA of TNFa under physiological conditions. Therefore, the cooperation of vitamin D and TNFa may play an important role in the control of immune cell growth (29).

We found a trend toward a significant correlation of the serum concentration of $25(\mathrm{OH}) \mathrm{VD}$ and the expression of mRNA of IL23 $\left(r^{2}=0.3, p=0.01\right)$ in CD patients in the inflamed terminal ileum as well as in UC patients $\left(\mathrm{r}^{2}=0.2, \mathrm{p}=0.01\right)$ in non-inflamed mucosa of sigma. In support of this interpretation, Faraji et al observed that the mRNA expression of IL17, IL23 and IFN- $\gamma$ decreased remarkably in mice that were administered VD3 before SLE induction. VD3 administration after the establishment of SLE failed to affect the expression of mRNA of IL 17, IL 23. Lastly, 


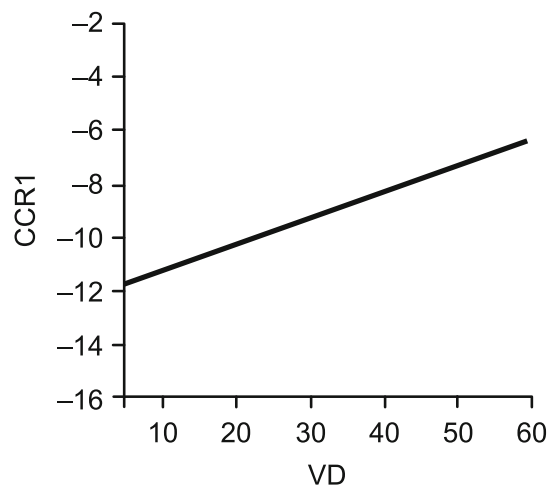

Influence of VD on the expression mRNA CCR1 in non-inflamed mucosa of sigma $r^{2}$ $=0.27, p=0.02$

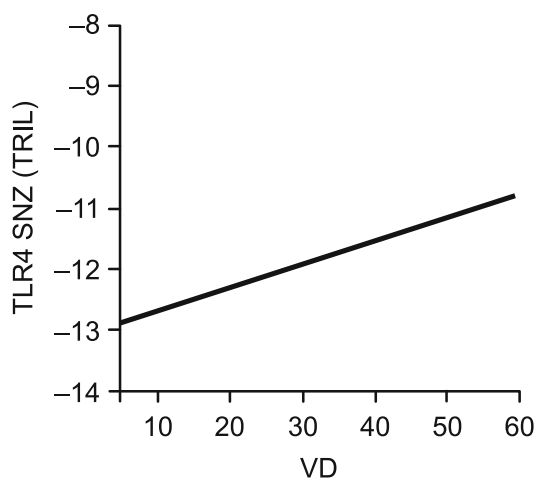

Influence of $V D$ on the expression mRNA TLR4 in non-inflamed mucosa of sigma $r^{2}$ $=0.18, p=0.02$

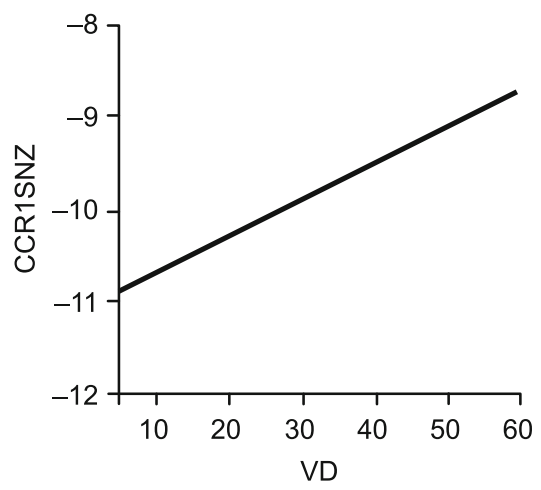

Influence of VD on the expression mRNA CCR5 in non-inflamed mucosa of sigma $r^{2}$ $=0.26 \mathrm{p}=0.003$

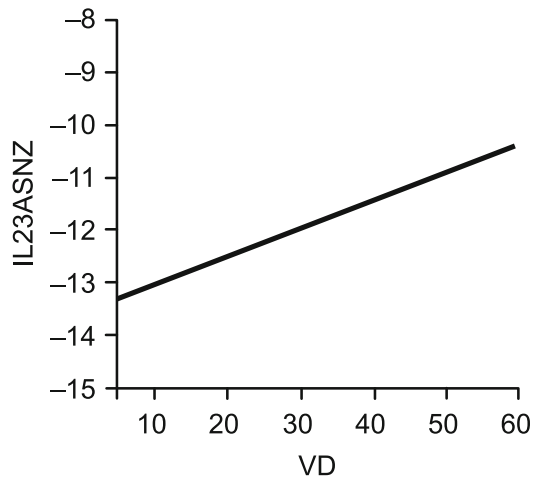

Influence of VD on the expression mRNA IL23 in non-inflamed mucosa of sigma $r^{2}=0.20$, $\mathrm{p}=0.01$

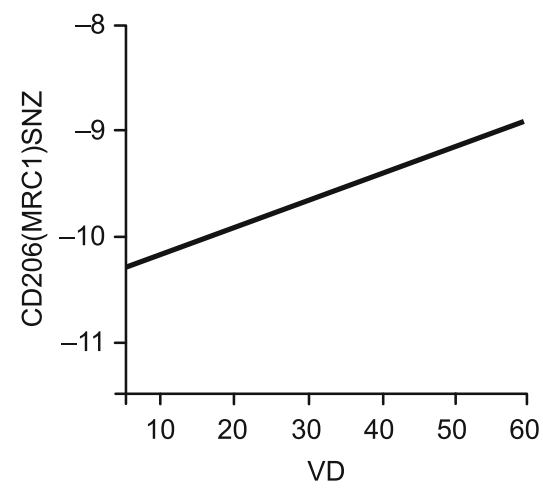

Influence of VD on the expression mRNA CD206 in non-inflamed mucosa of sigma $r^{2}$ $=0.19, p=0.02$

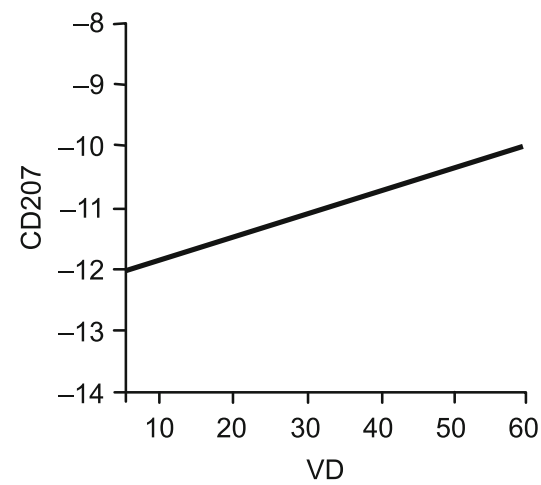

Influence of VD on the expression mRNA CD207 in non-inflamed mucosa of sigma $r^{2}$ $=0.18, p=0.02$

Fig. 3. The effect of vitamin D on mRNA expression mucosa of sigma in patients with UC.

VD pre-treatment may decrease the expression of mRNA of proinflammatory cytokines (30).

In our study, we found a trend toward a significant positive correlation between $25(\mathrm{OH}) \mathrm{VD}$ and the mRNA expression of TLR2 $\left(\mathrm{r}^{2}=0.17, \mathrm{p}=0.04\right)$ in inflamed mucosa of the terminal ileum in CD patients and TLR4 $\left(\mathrm{r}^{2}=0.18, \mathrm{p}=0.02\right)$ in non-inflamed sigma UC patients.

According our results, we suppose that VD may heighten TLR expression in preparation for a possible pathogen encounter.

A similar effect of VD is well documented in the study by Dionne et al They examined the effect of $1.25(\mathrm{OH}) \mathrm{VD}$ in the presence of MDP (muramyl dipeptide) and found that the co-stimulation of MDP and NOD-2 results in increased IL-10, IL-23 and TNF $\alpha$ in PBMC in CD patients $(\mathrm{p}<0.05)$. MDP as a ligand of NOD-2 induced the production of IL-23, IL-10 and TNF $\alpha$ (31).

\section{Conclusion}

UC patients had a significantly higher baseline expression of mRNA of cytokines TNF $\alpha$ transcription factor FOXP3, CCR5 in inflamed mucosa of sigma

In $\mathrm{CD}$ patients we observed a significantly higher expression of mRNA of IL-8 in inflamed mucosa of the terminal ileum. On the other hand, in the same group of patients, we observed no significant difference between the expression of mRNA of cytokines in inflamed and non-inflamed mucosa in sigma.

The serum of $25(\mathrm{OH}) \mathrm{VD}$ significantly positively correlates with the expression of mRNA of IL6 in inflamed mucosa of the terminal ileum in $\mathrm{CD}$ patients.

Although there is an increasing amount of evidence from human control studies that demonstrated the role of $25(\mathrm{OH}) \mathrm{VD}$ on the expression of mRNA of cytokines in human cells, additional clinical trials that investigate effect $25(\mathrm{OH}) \mathrm{VD}$ the expression of mRNA of cytokines in intestinal mucosa of IBD patients are needed.

\section{References}

1. Ko JK, Auyeung KK. Inflammatory bowel disease: etiology, pathogenesis and current therapy. Curr Pharm Des 2014; 20 (7): 1082-1096.

2. Xu XR, Liu CQ, Feng BS, Liu ZJ. Dysregulation of mucosal immune response in pathogenesis of inflammatory bowel disease. World J Gastroenterol 2014; 20 (12): 3255-3264.

3. Sanchez-Munoz F, Dominguez-Lopez A, Yamamoto-Furusho JK. Role of cytokines in inflammatory bowel disease. World J Gastroenterol 2008; 14 (27): 4280-4288. 
4. Hue S, Ahern P, Buonocore S, Kullberg MC, Cua DJ, McKenzie BS et al. Interleukin-23 drives innate and T cell-mediated intestinal inflammation. J Exp Med 2006; 203 (11): 2473-2483.

5. Strober W, Zhang F, Kitani A, Fuss I, Fichtner-Feigl S. Proinflammatory cytokines underlying the inflammation of Crohn's disease. Curr Opin Gastroenterol 2010; 26 (4): 310-317.

6. Bamias G, Kaltsa G, Ladas SD. Cytokines in the pathogenesis of ulcerative colitis. Discov Med 2011; 11 (60): 459-467.

7. Murata K, Fang C, Terao C, Giannopoulou EG, Lee YJ, Lee MJ et al. Hypoxia-Sensitive COMMD1 Integrates Signaling and Cellular Metabolism in Human Macrophages and Suppresses Osteoclastogenesis. Immunity 2017; 47 (1): 66-79 e5.

8. Neurath MF. Cytokines in inflammatory bowel disease. Nat Rev Immunol 2014; 14 (5): 329-342.

9. Ueno A, Ghosh A, Hung D, Li J, Jijon H. Th17 plasticity and its changes associated with inflammatory bowel disease. World J Gastroenterol 2015; 21 (43): 12283-12295.

10. Hlavaty T KA, Payer J. Vitamin D therapy in inflammatory bowel diseases: who, in what form, and how much? J Crohns Colitis 2015; 9 (2): 198-209.

11. Cantorna MT, Snyder L, Lin YD, Yang L. Vitamin D and 1,25 (OH)2D regulation of T cells. Nutrients 2015; 7 (4): 3011-3021.

12. Aranow C. Vitamin D and the immune system. J Investig Med 2011; 59 (6): 881-886.

13. Alhassan Mohammed H, Mirshafiey A, Vahedi H, Hemmasi G, Moussavi Nasl Khameneh A, Parastouei K et al. Immunoregulation of Inflammatory and Inhibitory Cytokines by Vitamin D3 in Patients with Inflammatory Bowel Diseases. Scand J Immunol 2017; 85 (6): 386-394.

14. Leskova Z KA, Soltys K, Stuchlík S, Sturdik I, Koller T, Huorka M, Hlavaty T. The influence of vitamin D on expression of cytokines mRNA in IBD. Journal of Crohn's and Colitis 2017; 11 (1): S384.

15. De Vita FL, Bauer J, Bautmans I, Shardell M, Cherubini A, Bondi G, Zuliani G, Bandinelli S, Pedrazzoni M, Dall'Aglio E, Ceda GP, Marcello. Relationship between vitamin D and inflammatory markers in older individuals. Age (Dordr) 2014; 36 (4): 9694.

16. Hlavaty T, Krajcovicova A, Koller T, Toth J, Nevidanska M, Huorka $\mathbf{M}$ et al. Higher vitamin D serum concentration increases health related quality of life in patients with inflammatory bowel diseases. World J Gastroenterol 2014; 20 (42): 15787-15796.

17. Sadeghian M, Saneei P, Siassi F, Esmaillzadeh A. Vitamin D status in relation to Crohn's disease: Meta-analysis of observational studies. Nutrition 2016; 32 (5): 505-514.

18. Krajcovicova AH, Leskova $\mathbf{Z}$ et al. Vitamin D status in IBD patients: a comparison of three different assays. JOURNAL OF CROHNS \& COLITIS 2015; 9: S184.
19. Matsuda R, Koide T, Tokoro C, Yamamoto T, Godai T, Morohashi T et al. Quantitive cytokine mRNA expression profiles in the colonic mucosa of patients with steroid naive ulcerative colitis during active and quiescent disease. Inflamm Bowel Dis 2009; 15 (3): 328-334.

20. Stallmach A, Giese T, Schmidt C, Ludwig B, Mueller-Molaian I, Meuer SC. Cytokine/chemokine transcript profiles reflect mucosal inflammation in Crohn's disease. Int J Colorectal Dis 2004; 19 (4): 308-315.

21. Bendix-Struve M, Bartels LE, Agnholt J, Dige A, Jorgensen SP, Dahlerup JF. Vitamin D3 treatment of Crohn's disease patients increases stimulated T cell IL-6 production and proliferation. Aliment Pharmacol Ther 2010; 32 (11-12): 1364-1372.

22. Diehl S, Rincon M. The two faces of IL-6 on Th1/Th2 differentiation. Mol Immunol 2002; 39 (9): 531-536.

23. Steensberg A, Fischer CP, Keller C, Moller K, Pedersen BK. IL-6 enhances plasma IL-1ra, IL-10, and cortisol in humans. Am J Physiol Endocrinol Metab 2003; 285 (2): E433-437.

24. Di Rosa M, Malaguarnera G, De Gregorio C, Palumbo M, Nunnari G, Malaguarnera L. Immuno-modulatory effects of vitamin D3 in human monocyte and macrophages. Cell Immunol 2012; 280 (1): 36-43.

25. Kimura A, Kishimoto T. IL-6: regulator of Treg/Th17 balance. Eur J Immunol 2010; 40 (7): 1830-1835.

26. Zhang Y, Leung DY, Richers BN, Liu Y, Remigio LK, Riches DW et al. Vitamin $\mathrm{D}$ inhibits monocyte/macrophage proinflammatory cytokine production by targeting MAPK phosphatase-1. J Immunol 2012; 188 (5): 2127-2135.

27. Eleftheriadis T, Antoniadi G, Liakopoulos V, Kartsios C, Stefanidis I, Galaktidou G. Paricalcitol reduces basal and lipopolysaccharideinduced (LPS) TNF-alpha and IL-8 production by human peripheral blood mononuclear cells. Int Urol Nephrol 2010; 42 (1): 181-185.

28. Chen Y, Liu W, Sun T, Huang Y, Wang Y, Deb DK et al. 1,25-Dihydroxyvitamin D promotes negative feedback regulation of TLR signaling via targeting microRNA-155-SOCS1 in macrophages. J Immunol 2013; 190 (7): 3687-3695.

29. Begue B, Wajant H, Bambou JC, Dubuquoy L, Siegmund D, Beaulieu JF et al. Implication of TNF-related apoptosis-inducing ligand in inflammatory intestinal epithelial lesions. Gastroenterology 2006; 130 (7): 1962-1974

30. Faraji F, Rastin M, Arab FL, Kalantari MR, Rabe SZ, Tabasi N et al. Effects of 1,25-dihydroxyvitamin D3 on IL-17/IL-23 axis, IFN-gamma and IL-4 expression in systemic lupus erythematosus induced mice model. Iran J Basic Med Sci 2016; 19 (4): 374-380.

31. Dionne S, Calderon MR, White JH, Memari B, Elimrani I, Adelson B et al. Differential effect of vitamin D on NOD2- and TLR-induced cytokines in Crohn's disease. Mucosal Immunol 2014; 7 (6): 1405-1415.

Received March 22, 2018. Accepted April 27, 2018. 